\title{
Effect of Cycling lon and Solvent on the Redox Chemistry of Substituted Quinones and Solvent-Induced Breakdown of the Correlation between Redox Potential and Electron-Withdrawing Power of Substituents
}

\author{
Huan Wang, Rikard Emanuelsson, Amitava Banerjee, Rajeev Ahuja, Maria Strømme, and Martin Sjödin*
}

Cite This: J. Phys. Chem. C 2020, 124, 13609-13617

Read Online

ACCESS |

Wll Metrics \& More

Article Recommendations

Supporting Information

ABSTRACT: Quinones have a capacity for high energy storage and exhibit facile and reversible electrochemistry in several widely different electrolytes. They are, therefore, one of the most popular compounds currently used in organic materials based electrical energy storage. Quinone electrochemistry is, however, strongly affected by the composition of the electrolyte. This report summarizes our systematic investigation of the redox chemistry of a series of quinones with electron-withdrawing and electron-donating substituents in aqueous solution and in acetonitrile $(\mathrm{MeCN})$ with tetrabutylammonium $\left(\mathrm{TBA}^{+}\right)_{-}, \mathrm{Li}^{+}$-, and $\mathrm{H}^{+}$-based electrolytes. As a general trend, proton cycling, $\mathrm{TBA}^{+}$cycling, and $\mathrm{Li}^{+}$cycling resulted in the highest, the lowest, and intermediate redox potentials, respectively. We attribute this trend to stabilization of the reduced state, namely benzene-1,4bis(olate) $\left(\mathrm{Q}^{2-}\right)$, by the different counterions. Density functional theory (DFT)

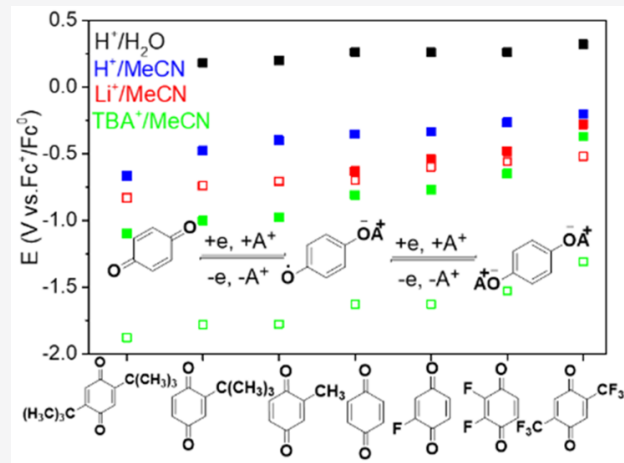
calculations showed that, in the fully reduced state, two $\mathrm{Li}^{+}$counterions accommodated $35 \%$ of the injected electron charges while proton counterions accommodated $69 \%$ of the injected charge, thus significantly stabilizing the reduced state. However, with the bulky $\mathrm{TBA}^{+}$as the cycling ion, this stabilization was not possible and the reduction potential was decreased. In addition, we showed that stabilization of the counterion also affected the Coulombic interaction between the successively injected charges, resulting in the well-known disproportionation of the semiquinone radical intermediate state with proton cycling, while $\mathrm{Li}^{+}$and $\mathrm{TBA}^{+}$cycling generally resulted in two consecutive redox reactions. Finally, we showed that the electrolyte strongly influences the effects of substitution with electron-donating and electron-withdrawing substituents. A strong relationship between the redox potential and the electron-withdrawing power of the substituent was observed in the $\mathrm{MeCN}$ solution. However, this relationship was completely lost in aqueous solution. The reason for the loss of the relationship was addressed using a DFT explicit-solvent model and is discussed.

\section{INTRODUCTION}

The increasing demand for electrical energy storage (EES) is currently satisfied by various types of lithium ion battery (LIB) technologies. The development of electric vehicles and the use of EES for stationary storage to mitigate variations in energy production from renewable energy sources raise concerns regarding (i) the availability of raw materials for LIBs, which currently rely on inorganic materials ( $\mathrm{Co}, \mathrm{Fe}, \mathrm{Mn}, \mathrm{Ni}$ ), (ii) the negative environmental impact of current LIB manufacturing, and (iii) the safety of current LIBs. ${ }^{1,2}$ It is therefore desirable to find alternative EES materials that can meet the requirements for eco-friendliness, raw material reserves, and safety, in addition to satisfying economic and technical demands for specific applications. Organic batteries are currently being widely investigated because of their sustainable life cycle, the ready availability of their building blocks, their low price, and the seemingly endless possibilities for tuning their material properties to meet specific end-user needs through molecular engineering. 3,4

Because of its high theoretical capacity $(496 \mathrm{mAh} / \mathrm{g}$ for benzoquinone), high redox stability, fast charge transfer, structural diversity, and compatibility with various electrolytes, ${ }^{5-7}$ quinone is one of the most frequently used organic redox-active components in organic matter based batteries. However, the quinone redox reaction is quite complex: it involves two electron transfer steps that are, in most cases, coupled to bond-breaking reactions. An understanding of how quinone redox chemistry can be modified by chemical

Received: April 24, 2020

Revised: June 4, 2020

Published: June 5, 2020

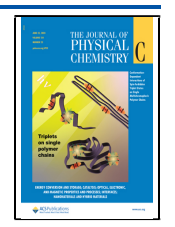


engineering, as well as by external factors such as the nature of the cycling ion and the solvent, is a crucial requirement for the design of high performance quinone-based battery materials.

From scattered reports in the literature, it is evident that the nature of the supporting electrolyte significantly affects quinone redox chemistry. For example, in acetonitrile $(\mathrm{MeCN})$ with a tetrabutylammonium hexafluorophosphate $\left(\mathrm{TBAPF}_{6}\right)$ electrolyte, quinone redox chemistry involves two reversible one-electron redox processes centered around -0.9 and $-1.7 \mathrm{~V}$ (vs $\left.\mathrm{Fc}^{+} / \mathrm{Fc}^{0}\right) .{ }^{8,9}$ In contrast, one reversible twoelectron process is observed at $-0.7 \mathrm{~V}\left(\mathrm{vs} \mathrm{Fc}^{+} / \mathrm{Fc}^{0}\right)^{10}$ with $\mathrm{Li}^{+}$ as the cycling ion and at $-0.2 \mathrm{~V}\left(\mathrm{vs} \mathrm{Fc}^{+} / \mathrm{Fc}^{0}\right)^{11,12}$ with $\mathrm{H}^{+}$as the cycling ion. It has been reported that adding an $\mathrm{OH}^{-}$base to hydroquinone $\left(\mathrm{QH}_{2}\right)$ in unbuffered aqueous solution can tune the redox peak negatively by changing the reduction product. ${ }^{13}$ Adding $\mathrm{QH}_{2}$ to benzoquinone $(\mathrm{Q})$ solution or a protonic solvent to an aprotic solvent, on the other hand, increases the benzoquinone reduction potential, possibly because of the formation of intermolecular hydrogen bonds. ${ }^{8,10,14}$ In an aqueous electrolyte, the accepted standard potential for $\mathrm{Q} / \mathrm{QH}_{2}$ is $0.7 \mathrm{~V}$ vs a normal hydrogen electrode (NHE) $\left(=0.3 \mathrm{~V} \mathrm{vs} \mathrm{Fc}^{+} / \mathrm{Fc}^{0}\right)$, but quinone redox chemistry is heavily dependent on the $\mathrm{pH}$ of the solution. The dissociation constants of the two hydroxyl groups in $\mathrm{QH}_{2}$ are $\mathrm{pK} K_{\mathrm{a}}=9.8$ and $\mathrm{p} K_{\mathrm{a} 2}=11.8$, and hence, below $\mathrm{pH} 9.8$, the two-electron reduction of $\mathrm{Q}$ is coupled to the uptake of two protons, resulting in the dependence of the quinone formal potential $\left(E^{\circ \prime}\right)$ on $\mathrm{pH}$ at $-59 \mathrm{mV} / \mathrm{pH}$ unit. Between $\mathrm{pH} 9.8$ and $\mathrm{pH}$ 11.8 , the product of $\mathrm{Q}$ reduction is $\mathrm{QH}^{-}$and thus the $E^{\circ \prime}$ is dependent on $\mathrm{pH}$ at $-29.5 \mathrm{mV} / \mathrm{pH}$ unit. Above $\mathrm{pH} 11.8$, the redox reaction is no longer proton-coupled; benzene-1,4bis(olate) $\left(\mathrm{Q}^{2-}\right)$ is the reduction product and $E^{\circ \prime}$ is independent of the $\mathrm{pH}^{13,15}$

The development of rational design strategies for active quinone-based electrode materials for use in various types of cycling chemistry requires a comprehensive understanding of the effects of the electrolyte composition on quinone electrochemistry. In addition, as quinones are used as both anode and cathode materials, ${ }^{16,17}$ it is also important to understand how the $E^{\circ \prime}$ of $Q$ can be tuned by substitution on the aromatic ring. It is well-known that quinone derivatives with electron-withdrawing substituents on the aromatic ring can push $E^{\circ \prime}$ positively while electron-donating substitutions can pull it negatively. ${ }^{18}$ However, a systematic study of how these substitution effects are affected by different cycling ions and solvents has not previously been conducted. This paper summarizes how a series of quinone derivatives were synthesized and characterized in four different electrolytes. In accordance with the literature data, we found that $E^{\circ \prime}$ followed the trend $\mathrm{TBA}^{+}<\mathrm{Li}^{+}<\mathrm{H}^{+}$in an $\mathrm{MeCN}$ solvent, and the $E^{\circ \prime}$ of quinone shifted positively with the substituent's electronwithdrawing ability. Surprisingly, the potential to shift $E^{\circ \prime}$ by substitution was largely lost in aqueous solution. As a result of density functional theory (DFT) calculations with explicit treatment of the surrounding water, we attributed this effect to electron donation from solvent water molecules counteracting the effect of substitution.

\section{EXPERIMENTAL SECTION}

All solvents and electrolytes were purchased from SigmaAldrich and were used without further purification except for acetonitrile $(\mathrm{MeCN})$, which was dried over molecular sieves (3 $\AA$ ) prior to use. The listed compounds $\mathbf{1 - 4}$ in Figure $2 \mathrm{~b}$ were purchased from Sigma-Aldrich and used as received. Compounds 5-7 were synthesized by the method described, as previously reported. ${ }^{19}$

2.1. Electrochemical Characterization. All electrochemical characterizations were conducted on an Autolab PGSTAT302N apparatus (Ecochemie, The Netherlands) in a three-electrode setup with a Pt wire as counter electrode and a glassy carbon (GC) disk electrode (diameter $3 \mathrm{~mm}, \mathrm{BASI}$, USA) as the working electrode unless specified otherwise. In organic solutions, the reference electrode consisted of an $\mathrm{Ag}$ wire immersed in a $0.01 \mathrm{M} \mathrm{AgNO}_{3} / \mathrm{MeCN}$ solution with 0.1 $\mathrm{M}$ of the relevant supporting electrolyte, which was kept in a separate compartment. $\mathrm{An} \mathrm{Ag} / \mathrm{AgCl}(3 \mathrm{M} \mathrm{KCl})$ reference electrode was used in aqueous solution. All experiments using

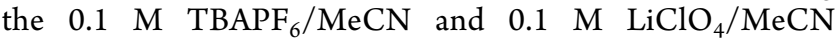
electrolytes were conducted in an $\mathrm{N}_{2}$-filled glovebox. All experiments using the $0.1 \mathrm{M}$ pyridium triflate $/ 0.1 \mathrm{M}$ pyridine/ $\mathrm{MeCN}$ and $0.5 \mathrm{M} \mathrm{H}_{2} \mathrm{SO}_{4} / \mathrm{H}_{2} \mathrm{O}$ electrodes were conducted in $\mathrm{N}_{2}$-purged solutions, and $\mathrm{N}_{2}$ pressure over the electrolyte was sustained throughout the experiments.

Each sample was characterized in solution, with an analyte concentration of $0.1-5 \mathrm{mM}$, by cyclic voltammetry $(\mathrm{CV})$ and square wave voltammetry (SWV). A low quinone concentration was used to avoid dimerization and precipitation, which can affect the redox reaction. ${ }^{20-22} \mathrm{~A}$ frequency of $8 \mathrm{~Hz}$ and an amplitude of $20 \mathrm{mV}$ were used for both the reduction and oxidation processes in SWV. The reference electrode was calibrated against ferrocene through $\mathrm{CV}$ measurement after each set of experiments. All $E^{\circ \prime}$ data are reported against ferrocene (vs $\mathrm{Fc}^{+} / \mathrm{Fc}^{0}$ ), which is at $3.25 \mathrm{~V}$ vs $\mathrm{Li}^{+} / \mathrm{Li}^{0}$.

2.2. Computational Details. All quantum chemistry calculations were performed using DFT with the hybrid density functional B3LYP ${ }^{23-25}$ as implemented in the Jaguar 7.7 software package and at the level of the $6-311 G^{* *}$ basis $\operatorname{set}^{26,27}$ to understand the electrochemical behavior of the quinone derivatives. For all solvents $\left(\mathrm{MeCN}\right.$ and $\mathrm{H}_{2} \mathrm{O}$ based), a polarizable continuum solvation model (PCM) was used to calculate the Mulliken charge on each atom in the optimized geometries. ${ }^{28}$ In $\mathrm{LiClO}_{4} / \mathrm{MeCN}$ and pyridium triflate/ pyridine $/ \mathrm{MeCN}, \mathrm{Li}^{+}$and $\mathrm{H}^{+}$cations were introduced to balance the negative charge of semiquinone $\left(\mathrm{SQ}^{\bullet-}\right)$ and reduced $\mathrm{Q}^{2-}$. No cation was included in the $\mathrm{TBAPF}_{6} / \mathrm{MeCN}$ electrolyte, as the bulky $\mathrm{TBA}^{+}$cannot coordinate to $\mathrm{SQ}^{\bullet-}$ or $\mathrm{Q}^{2-}$. Two methods were used for the aqueous solvent: the PCM and explicit inclusion of solvent molecules in conjunction with the PCM. The PCM solvation model represents interactions between a quinone molecule and the solvent by placing the molecule in a cavity of the solvent with a specific dielectric constant; this method cannot predict specific interactions with the solvent molecule. In the explicit/PCM solvent model, four $\mathrm{H}_{2} \mathrm{O}$ molecules are introduced around the investigated quinone molecule; this method can predict specific quinone $-\mathrm{H}_{2} \mathrm{O}$ interactions.

\section{RESULTS AND DISCUSSION}

\subsection{Effects of Electrolyte Cation and Solvent on the} Formal Potential $\left(E^{\circ \prime}\right)$ of Benzoquinone (Q). Figure 1 shows the CV and SWV responses of $Q$ (compound 4 in Figure $2 \mathrm{~b}$ ) characterized in the four electrolytes, $\mathrm{TBAPF}_{6} /$ $\mathrm{MeCN}, \mathrm{LiClO}_{4} / \mathrm{MeCN}$, pyridium triflate/pyridine/MeCN, and $\mathrm{H}_{2} \mathrm{SO}_{4} / \mathrm{H}_{2} \mathrm{O}$. The $E^{\circ \prime}$ values for $\mathrm{Q}$ in the above electrolytes were evaluated using different methods since different conditions were required for each specific electrolyte, 


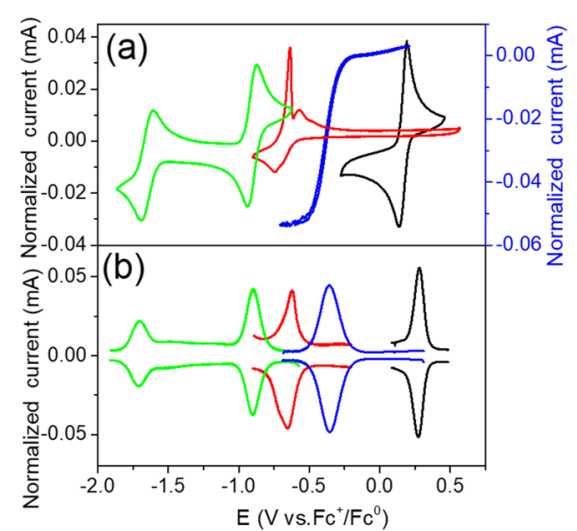

Figure 1. (a) Cyclic voltammetry and (b) square wave voltammetry (SWV) results for $0.1 \mathrm{mM}$ benzoquinone $(\mathrm{Q})$ in $\mathrm{TBAPF}_{6} / \mathrm{MeCN}$ (green), $\mathrm{LiClO}_{4} / \mathrm{MeCN}$ (red), $\mathrm{H}_{2} \mathrm{SO}_{4} / \mathrm{H}_{2} \mathrm{O}$ (black), or a $5 \mathrm{mM}$ quinone solution in pyridium triflate/pyridine/ $\mathrm{MeCN}$ (blue). All measurements were conducted using a bare glassy carbon working electrode at a scan rate of $0.1 \mathrm{~V} / \mathrm{s}$ except in pyridium triflate/ pyridine $/ \mathrm{MeCN}$, where a scan rate of $0.01 \mathrm{~V} / \mathrm{s}$ was used. SWV was conducted at a frequency of $8 \mathrm{~Hz}$.

as detailed below. In $\mathrm{TBAPF}_{6} / \mathrm{MeCN}$ and in $\mathrm{H}_{2} \mathrm{SO}_{4} / \mathrm{H}_{2} \mathrm{O}, E^{\circ}$ was evaluated from the average value of the anodic and cathodic peak potentials in $\mathrm{CV}$ and SWV. In $\mathrm{LiClO}_{4} / \mathrm{MeCN}$, $E^{\circ \prime}$ was evaluated by fitting the cathodic SWV peak. In pyridium triflate/pyridine/ $\mathrm{MeCN}, E^{\circ \prime}$ was evaluated from the inflection point from the anodic and cathodic scans in $\mathrm{CV}$ and the cathodic peak in SWV.

In the $\mathrm{TBAPF}_{6} / \mathrm{MeCN}$ electrolyte, using a scan rate of 0.1 $\mathrm{V} / \mathrm{s}, \mathrm{CV}$ showed two pairs of redox peaks centered at -0.91 and $-1.71 \mathrm{~V}$, respectively. Corresponding peaks were also evident in the SWV response. The first reduction process, centered at $-0.91 \mathrm{~V}$, corresponds to the redox conversion from the quinone to the semiquinone radical $\left(\mathrm{Q}^{\bullet-}\right)$ (step 1 depicted in Scheme 1a). The moderate peak separation $(66 \mathrm{mV})$ and the similar anodic and cathodic peak currents $\left(i_{\mathrm{p}(\mathrm{red})} / i_{\mathrm{p}(\mathrm{ox})}=1\right)$ after background current subtraction suggest that the redox process is chemically reversible. In the second reduction process, corresponding to the redox conversion between $\mathrm{Q}^{\bullet-}$ and $\mathrm{Q}^{2-}$ (step 2 depicted in Scheme 1a), the anodic and cathodic peak currents were also similar $\left(i_{\mathrm{p}(\mathrm{red})} / i_{\mathrm{p}(\mathrm{ox})}=1\right)$ after background current subtraction but there was a larger peak separation $(89 \mathrm{mV})$. Using the average anodic and cathodic peak potentials from the CV and SWV data, $E^{\circ \prime}$ for the $Q^{\bullet-}$ / $\mathrm{Q}^{2-}$ redox reaction was evaluated as $-1.71 \mathrm{~V}$.

In the $\mathrm{LiClO}_{4} / \mathrm{MeCN}$ electrolyte, a scan rate of $0.1 \mathrm{~V} / \mathrm{s}$ was used to conduct the $\mathrm{CV}$ measurements. The cathodic scan exhibited a broad reduction peak, and the anodic scan exhibited a sharp peak at $-0.61 \mathrm{~V}$ and a following peak at $-0.53 \mathrm{~V}$. SWV also exhibited a broadened reduction peak and a sharp anodic peak. The sharp anodic peak seen in the CV is attributed to a surface peak originating from insoluble lithium benzene-1,4-bis(olate) ( $\left.\mathrm{Li}_{2} \mathrm{Q}\right)$ salt deposited on the electrode surface upon reduction. This interpretation was verified by pretreatment at $-1.05 \mathrm{~V}$ followed by a cathodic SWV sweep which gave a corresponding reductive surface peak centered at $-0.85 \mathrm{~V}$ that increased with pretreatment time (Figure S1). It was also confirmed by the disappearance of the reductive surface peak centered at $-0.85 \mathrm{~V}$ after pretreatment at $0.75 \mathrm{~V}$ where insoluble $\mathrm{Li}_{2} \mathrm{Q}$ was fully transformed to soluble $\mathrm{Q}$. As the anodic sweep is obscured by surface deposition, $E^{\circ \prime}$ was estimated from the reduction scan in SWV. A close inspection of the SWV response showed that the peak was composed of two overlapping peaks (Figure S2). By fitting the response to two Gaussian curves, $E^{\circ \prime}$ values for the two redox conversions were estimated as -0.63 and $-0.70 \mathrm{~V}$. We interpreted the two peaks as the two successive one-electron reductions of $\mathrm{Q}$ to $\mathrm{Li}_{2} \mathrm{Q}$ depicted in Scheme $1 \mathrm{~b}$, and hence, the approximate $E^{\circ \prime}$
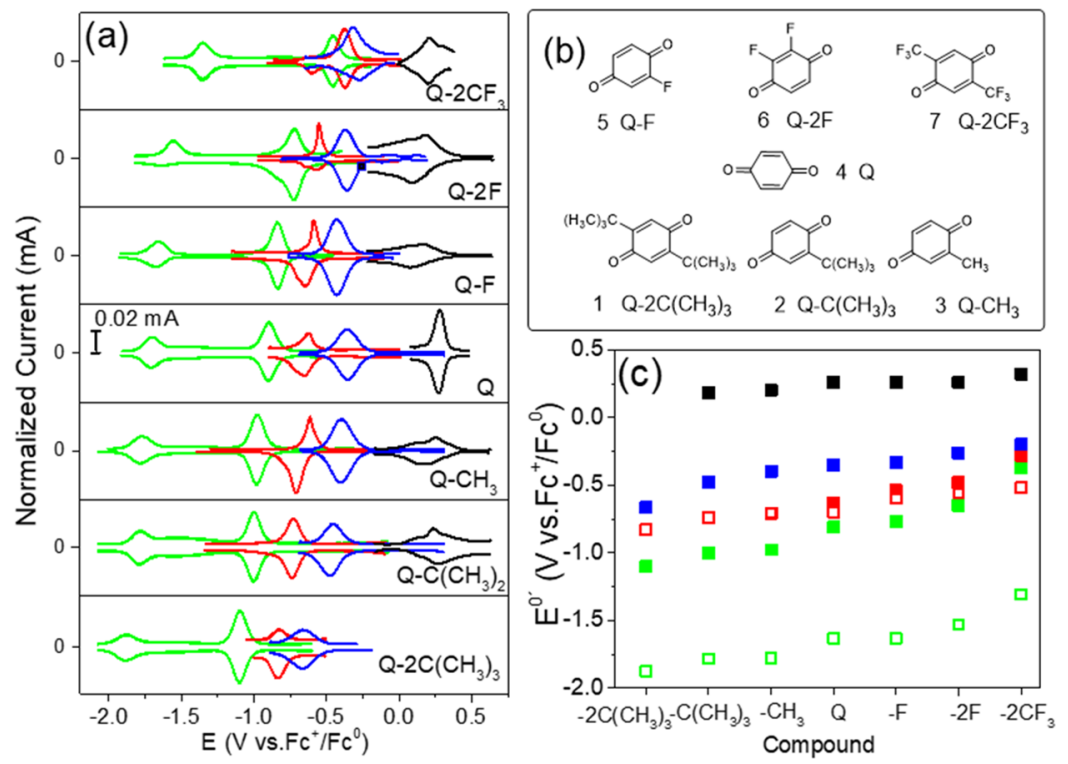

Figure 2. (a) Square wave voltammetry (SWV) of $0.1 \mathrm{mM}$ quinone derivatives in $\mathrm{TBAPF}_{6} / \mathrm{MeCN}$ (green), $\mathrm{LiClO}_{4} / \mathrm{MeCN}\left(\mathrm{red}\right.$ ), and $\mathrm{H}_{2} \mathrm{SO}_{4} /$ $\mathrm{H}_{2} \mathrm{O}$ (black), and $5 \mathrm{mM}$ quinone derivatives in pyridium triflate/pyridine/MeCN (blue). SWV was conducted at a frequency of $8 \mathrm{~Hz}$. All the working electrodes were bare glassy carbon electrodes. (b) Structure of the quinone-based compounds. (c) $E^{\circ \prime}$ versus substituents on the quinone aromatic ring in different electrolytes. Black solid square is $E^{\circ \prime}$ in $\mathrm{H}_{2} \mathrm{SO}_{4} / \mathrm{H}_{2} \mathrm{O}$, blue solid square is $E^{\circ \prime}$ in pyridium triflate/pyridine/MeCN, and red solid square and hollow square are $E^{\circ \prime}$ of the first and second reductions in $\mathrm{LiClO}_{4} / \mathrm{MeCN}$, respectively. Green solid square and hollow square are $E^{\circ \prime}$ of first and second reductions in $\mathrm{TBAPF}_{6} / \mathrm{MeCN}$, respectively. 
Scheme 1. Quinone Redox Reactions in (a) $\mathrm{TBAPF}_{6} / \mathrm{MeCN}$, (b) $\mathrm{LiClO}_{4} / \mathrm{MeCN}$, and (c) $\mathrm{H}^{+}$-Containing $\mathrm{MeCN}$ or $\mathrm{H}_{2} \mathrm{O}$ Solution in a Polarizable Continuum Model with a Corresponding Solvent Cage ${ }^{a}$
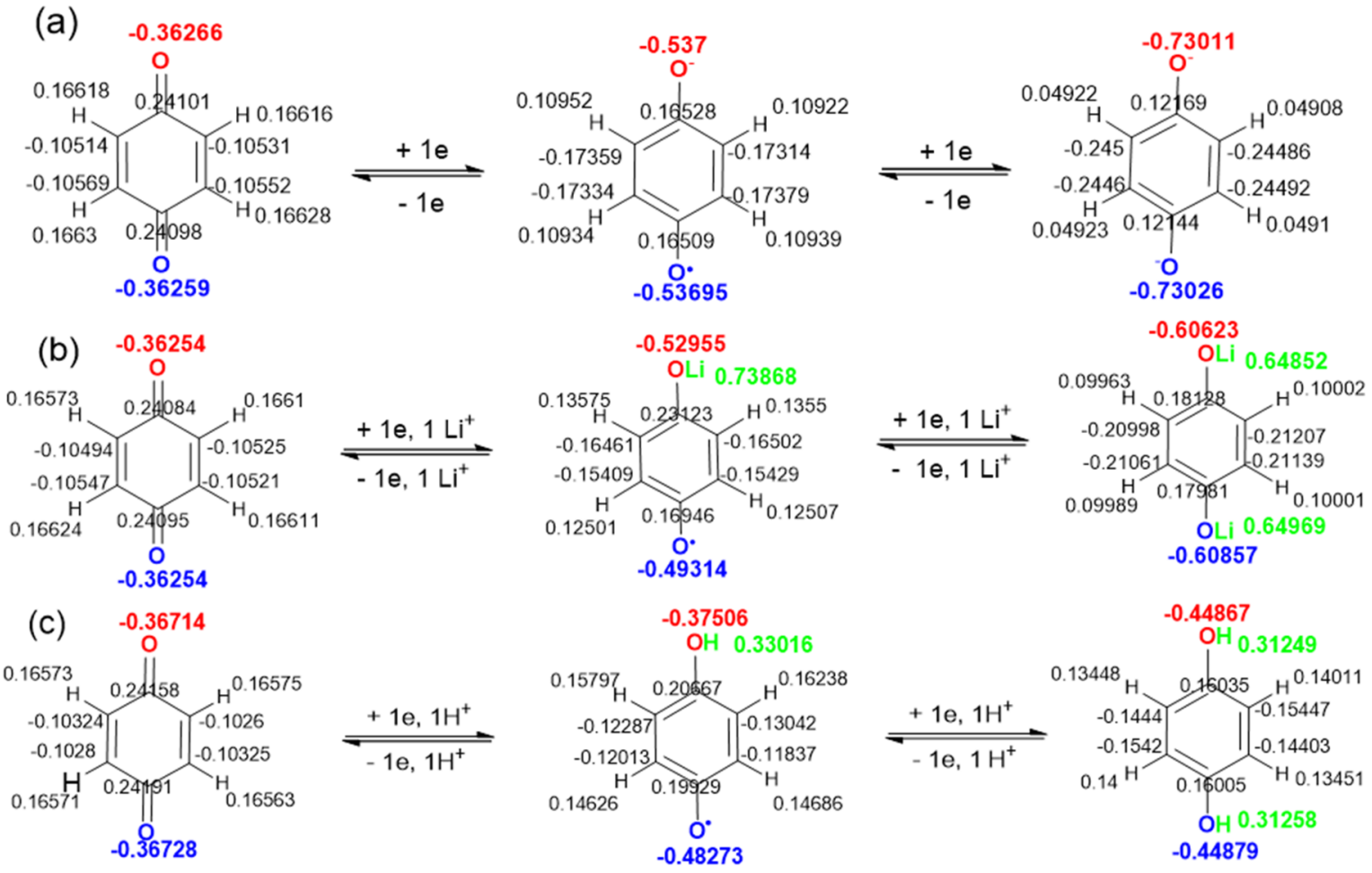

${ }^{a_{\text {The }}}$ numbers correspond to the calculated Mulliken charge on each atom. The two oxygen atoms are colored red and blue, respectively, while charge-balancing ions are green for clarity.

values for these reactions were -0.63 and $-0.70 \mathrm{~V}$, respectively. Compared to the value for $\mathrm{TBAPF}_{6} / \mathrm{MeCN}, E^{\circ}$ shifted positively by 0.28 and $1.01 \mathrm{~V}$ for the first and second reductions, respectively, suggesting that the lithium ion significantly stabilized the reduced states. It is also worth noting that the separation between the two $E^{\circ \prime}$ values in the $\mathrm{Li}^{+}$-based electrolyte $(0.07 \mathrm{~V})$ was much smaller than the separation in the $\mathrm{TBA}^{+}$-based electrolyte $(0.80 \mathrm{~V})$, suggesting that the $\mathrm{Li}_{2} \mathrm{Q}$ state was stabilized to a greater extent than the radical state $\left(\mathrm{LiQ}^{\bullet}\right)$. The reason for this is addressed in section 3.3.1.

As stated in the Introduction, quinone reduction is coupled to proton uptake in aqueous solution. This was also evident in organic solvents when pyridinium/pyridine acid-base couples were in the electrolyte. As the solvent in the pyridium triflate/ pyridine/MeCN electrolyte was the same as that in the experiments discussed above, the effect of the cycling ion on quinone redox chemistry could be studied in isolation from solvent effects. The quinone redox process in the pyridium triflate/pyridine/ $\mathrm{MeCN}$ electrolyte was, however, kinetically slow, with a large peak split of $320 \mathrm{mV}$ at $0.1 \mathrm{~V} / \mathrm{s}$ (Figure S3). This is not surprising, as the overall reaction, going from $Q$ to $\mathrm{QH}_{2}$, requires the encounter of one quinone with two pyridinium ions as well as the transfer of two electrons and two protons. Therefore, a slow scan rate of $0.01 \mathrm{~V} / \mathrm{s}$ was used for $\mathrm{CV}$ measurement to suppress any kinetic effects. In this case, the current showed a sigmoidal response and we interpreted the inflection point of the sigmoidal curve as the $E^{\circ \prime}$ of the redox reaction. Only one inflection was observed, and hence the reaction corresponds to the well-known $2 \mathrm{e} / 2 \mathrm{H}^{+}$ redox conversion going from the fully oxidized state ( $Q$ ) to the fully protonated, doubly reduced $\mathrm{QH}_{2}$ state. Also SWV measurement showed only one redox peak, suggesting that the semiquinone radical state depicted in Scheme $1 \mathrm{c}$ is unstable with respect to disproportionation. $E^{\circ \prime}$, as evaluated from the average inflection point during anodic and cathodic sweeps in both CV and SWV, was $-0.33 \mathrm{~V}$. Compared to $\mathrm{Li}^{+}$ cycling, proton cycling showed a positive shift of the $E^{\circ \prime}$, suggesting that the proton further stabilized the quinone reduced state. The inversion of the $E^{\circ \prime}$ for the first and second reductions suggests, again, that the fully reduced state was stabilized to a greater extent than the semiquinone state. When comparing the quinone $E^{\circ \prime}$ for $\mathrm{TBA}^{+}$and $\mathrm{Li}^{+}$cycling with that for proton cycling, it is important to note that in the latter case $E^{\circ \prime}$ depends on the proton source; i.e., it has been shown that the quinone $E^{\circ}$ depends linearly on the $\mathrm{p} K_{\mathrm{a}}$ of the exact pyridinium ion used with a $-59 \mathrm{mV} / \mathrm{p} K_{\mathrm{a}}$ correlation. $^{11}$

A scan rate of $0.1 \mathrm{~V} / \mathrm{s}$ was used to conduct the $\mathrm{CV}$ measurement in the $\mathrm{H}_{2} \mathrm{SO}_{4} / \mathrm{H}_{2} \mathrm{O}$ electrolyte. As with the pyridium triflate/pyridine/MeCN electrolyte, only one pair of redox peaks $(0.29 \mathrm{~V} / 0.23 \mathrm{~V})$, separated by $56 \mathrm{mV}$, was observed. Although the peak separation between the anodic and cathodic peaks was somewhat bigger than the theoretical value $(28 \mathrm{mV})$, the similar anodic and cathodic peak currents suggests a chemically reversible redox reaction. Also, SWV showed only one redox peak during anodic and cathodic sweeps and we interpreted the redox peak as originating from the $2 \mathrm{e} / 2 \mathrm{H}^{+}$redox conversion between $\mathrm{Q}$ and $\mathrm{QH}_{2}$, in agreement with a previous study. ${ }^{29} E^{\circ \prime}$ was evaluated as 0.26 $\mathrm{V}$ from the average peak potential of both CV and SWV measurements. The reported data for a standard quinone redox potential in aqueous acid electrolyte is $0.69 \mathrm{~V}$ vs NHE, 
suggesting an $E^{\circ \prime}$ of $0.67 \mathrm{~V}$ vs $\mathrm{NHE}$ in $0.5 \mathrm{M} \mathrm{H}_{2} \mathrm{SO}_{4} / \mathrm{H}_{2} \mathrm{O}$ electrolyte ( $\mathrm{pH} 0.3$ ). The corresponding $\mathrm{E}^{\mathrm{O} \prime}$ values are $0.48 \mathrm{~V}$ (vs $\mathrm{Ag} / \mathrm{AgCl}$ ) and $0.26 \mathrm{~V}\left(\mathrm{vs} \mathrm{Fc}^{+} / \mathrm{Fc}^{0}\right.$ ), in excellent agreement with the experiment results presented here.

To conclude with respect to the effects of cycling ion and solvent, we first note that the $E^{\circ \prime}$ of an unsubstituted quinone spanned a voltage range of almost $2 \mathrm{~V}$ and hence note that quinone electrochemistry is heavily dependent on the cycling ion and the solvent. The cycling ion effect was the most prominent, and we have shown that the $E^{\circ \prime}$ increased gradually in the order $\mathrm{TBA}^{+}<\mathrm{Li}^{+}<\mathrm{H}^{+}$. As, in all cases, the energy of the oxidized state $Q$ was the same, this relationship was the result of the stabilizing effect of the coordination ions; $\mathrm{Li}^{+}$and $\mathrm{H}^{+}$ coordinated with the reduced quinone state while $\mathrm{TBA}^{+}$did not. We also conclude that this stabilization effect for the fully reduced state was significantly stronger than for the intermediate radical state, resulting in a decreased separation between the first and second reductions with $\mathrm{Li}^{+}$and a potential inversion for proton cycling.

3.2. Substituent Effects on the $E^{\circ \prime}$ of $Q$. In order to study the effects of substitution on quinone redox chemistry and to investigate how these substitution effects might vary with the cycling ions, we characterized a series of quinone derivatives 1-7 (Figure 2b) using electron-withdrawing and electron-donating groups in the same electrolytes with SWV (Figure 2a) and CV (Figures S4-S7.). The experimental $E^{\circ \prime}$ was obtained using the same methods as above and is shown in Table S1. Figure 2c shows the effects of substitution in the different electrolytes, presenting the $E^{\circ \prime}$ values for different compounds against substitution. The compounds are ordered by the substituent's electron-withdrawing power (increasing from bottom to top in Figure 2a and from left to right in Figure $2 \mathrm{c})$. Although the inductive effect of $-\mathrm{F}$ is stronger than that of $-\mathrm{CF}_{3}$, we ranked the electron-withdrawing ability of $-\mathrm{CF}_{3}$ higher because of the electron-donating property of $-\mathrm{F}$ through the resonance effect. ${ }^{30,31}$

In the $\mathrm{TBAPF}_{6} / \mathrm{MeCN}$ electrolyte, all quinone derivatives showed two individual one-electron processes and both redox peaks shifted positively with electron-withdrawing substitutions (Figure 2a, green). To be more specific, for the $-2 \mathrm{C}\left(\mathrm{CH}_{3}\right)_{3}$ substitution to the $-2 \mathrm{CF}_{3}$ substitution, the $E^{\circ}$ of the first reduction process gradually shifted from -1.10 to $-0.37 \mathrm{~V}$, and the $E^{\circ \prime}$ of the second reduction process shifted from -1.88 to $-1.31 \mathrm{~V}$. Hence, we conclude that the first redox process is more sensitive to substitution, with a $0.73 \mathrm{~V}$ difference between the $-2 \mathrm{C}\left(\mathrm{CH}_{3}\right)_{3}$-substituted compound and the $-2 \mathrm{CF}_{3}$-substituted compound, while the second redox process only shifted by $0.57 \mathrm{~V}$. The same general trend was observed in the $\mathrm{LiClO}_{4} / \mathrm{MeCN}$ electrolyte. That is, $E^{\circ \prime}$ shifted toward a higher potential as the electron-withdrawing nature of the substituents increased, and $E^{\circ \prime}$ for the first reduction was more affected than $E^{\circ \prime}$ for the second reduction. However, the dependence was weaker than that in the $\mathrm{TBAPF}_{6} / \mathrm{MeCN}$ electrolyte. Going from a $-2 \mathrm{C}\left(\mathrm{CH}_{3}\right)_{3}$ substitution to a $-2 \mathrm{CF}_{3}$ substitution, positive shifts of 0.55 and $0.31 \mathrm{~V}$ were observed for the first and second reductions, respectively; this was a smaller shift than in the $\mathrm{TBAPF}_{6} / \mathrm{MeCN}$ electrolyte $(0.73$ and $0.57 \mathrm{~V})$. It was notable that, while the two redox processes were well separated with electron-withdrawing substituents, the weaker dependence of the second reduction brought about a potential inversion with less-electron-withdrawing substituents, i.e., substituents with electron-withdrawing power less than hydrogen $\left(-\mathrm{CH}_{3},-\mathrm{C}\left(\mathrm{CH}_{3}\right)_{3}\right.$, and $\left.-2 \mathrm{C}\left(\mathrm{CH}_{3}\right)_{3}\right)$. For this reason, quinone derivatives with electron-donating groups showed only one reduction peak, the unsubstituted quinone exhibited two slightly separated reduction peaks at -0.70 and $-0.64 \mathrm{~V}$, and the two reduction peaks were distinctively separated $(-0.52$ and $-0.28 \mathrm{~V})$ with $-2 \mathrm{CF}_{3}$ substitution.

In the protonic pyridium triflate/pyridine/ $\mathrm{MeCN}$ electrolyte, all the quinone derivatives exhibited only one redox process in SWV and CV (Figure S6). $E^{\circ}$ also shifted positively upon electron-withdrawing substitution, as with the $\mathrm{LiClO}_{4}$ / $\mathrm{MeCN}$ and $\mathrm{TBAPF}_{6} / \mathrm{MeCN}$ electolytes. Regarding the substitution effect on $E^{\circ \prime}$, from $-2 \mathrm{C}\left(\mathrm{CH}_{3}\right)_{3}$ substitution to $-2 \mathrm{CF}_{3}$ substitution, $E^{\circ \prime}$ was positively shifted by $0.47 \mathrm{~V}$. This value was a bit lower than those in $\mathrm{TBAPF}_{6} / \mathrm{MeCN}$ and $\mathrm{LiClO}_{4} / \mathrm{MeCN}$. This was especially apparent for the $-2 \mathrm{CF}_{3}$ substituted quinone, where the $E^{\circ \prime}$ of the first reduction showed very limited dependence on the cycling ion, as Q/ $\mathrm{QH}_{2}, \mathrm{Q} / \mathrm{QLi}^{\bullet}$, and $\mathrm{Q} / \mathrm{Q}^{\bullet-}$ had almost the same $E^{\circ \prime}$, suggesting that counterion stabilization becomes less important as the electron density of the quinone is reduced.

In the aqueous $\mathrm{H}_{2} \mathrm{SO}_{4} / \mathrm{H}_{2} \mathrm{O}$ electrolyte, all the characterized quinone derivatives showed only one redox process in SWV and CV (Figure S7), suggesting that the semiquinone radical was also unstable with respect to disproportionation for all the quinone derivatives investigated in this electrolyte. Interestingly, and somewhat unexpectedly, $E^{\circ \prime}$ in aqueous solution was almost invariant to substitution (Figure 2c). As a similar invariance to substitution was not observed with proton cycling in the $\mathrm{MeCN}$ solution, i.e., in the protonic pyridium triflate/pyridine/MeCN electrolyte, we conclude that this breakdown of the Hammett substitution correlation is related to specific solvent interactions rather than the cycling ion. The origin of this interaction is addressed below through quantum chemical calculations by inclusion of explicit solvent molecules (section 3.3.2).

3.3. DFT Calculation. 3.3.1. Charge Delocalization upon Reduction. DFT calculations were performed to understand the effect of cycling ions and substitution on quinone redox chemistry. We first addressed the effect of cycling ions; specifically, we investigated the experimentally observed changes from two sequential redox reactions with $\mathrm{TBA}^{+}$as the cycling ion to a $2 \mathrm{e} / 2 \mathrm{H}^{+}$redox reaction with proton cycling and an intermediate situation with $\mathrm{Li}^{+}$as the cycling ion. Intuitively, this effect should be related to variations in the Coulombic interaction of the first and second injected charges. To assess this hypothesis computationally, we calculated the Mulliken charges for all atoms in the different redox states with different charge-balancing ions for the reduced states (Scheme 1) for the unsubstituted quinone (Tables $S 2-S 4$ ). In order to estimate the interaction of the injected charges, we first calculated the change in net charge going from the fully oxidized state to the semiquinone radical state. With $\mathrm{TBA}^{+}$we assumed that no counterions balanced the negative charge as the bulky $\mathrm{TBA}^{+}$has limited access to redox sites on quinone, and hence the net charge of the semiquinone was -1 in this case. From the Mulliken charges, it is clear that this charge is evenly spread, with each of the two oxygens accommodating $17.5 \%$ of the injected charge while the remaining $65 \%$ was accommodated by the benzene ring. The same situation was seen during the second reduction, now with each of the oxygen atoms accommodating 19\% of the injected charge and the benzene ring accommodating $62 \%$ of the charge. It is thus clear that the two charges occupy the same positions. 
With $\mathrm{Li}^{+}$as cycling ion, the situation was surprisingly similar. In the energy-minimized structure for the semiquinone radical, the lithium ion coordinated with one of the oxygen atoms, as expected. This oxygen accommodated $16.7 \%$ of the injected charge. Somewhat surprisingly, the change in charge on the second oxygen was quite similar, corresponding to $13 \%$ of the charge injected. Also in this case the charge was thus rather evenly spread over the molecule rather than being localized around the binding site of the lithium ion. The difference in separation between the redox peaks corresponding to the first and second reductions with $\mathrm{TBA}^{+}$and $\mathrm{Li}^{+}$cycling was, instead, traced to the charge accommodated by the lithium ion itself. During the first reduction, the additional lithium ion accommodated $26 \%$ of the injected charge, leaving only $44 \%$ of the charge to the benzene ring as compared to $65 \%$ with $\mathrm{TBA}^{+}$. During the second reduction, the second lithium ion accommodated $35 \%$ of the injected charge while the benzene ring and the two oxygen atoms only took 35 and $21 \%$, respectively. The remaining $9 \%$ was accommodated by the first lithium ion. As a significant fraction of the first and second charges was accommodated by separate lithium ions, the Coulombic interaction between the injected charges should be lower for lithium cycling than for $\mathrm{TBA}^{+}$cycling. In order to reach a qualitative estimation of the Coulombic interaction between the first and second injected charges, the change in charge experienced by each atom was calculated for the first and second reductions, as depicted in Tables S2-S4. The charge change associated with the first reduction provides a simple means for estimating the probability of finding the injected electron at a certain position (or atom) in the molecule, while the charge change associated with the second reduction estimates the position of the second injected electron. Intuitively, the Coulombic interaction between the first and second injected charges should be highest when the two charges occupy the same position. An interaction term was therefore calculated by multiplying the change in charge for the first and second reductions of each atom and creating a sum of interaction terms for the entire molecule. The interaction terms thus evaluated were 0.11 for $\mathrm{TBA}^{+}$cycling and 0.07 for $\mathrm{Li}^{+}$cycling, showing that the Coulombic interaction between the first and second charges is significantly reduced with $\mathrm{Li}^{+}$as the charge-balancing ion, and thus accounting for the reduced separation between the first and second $E^{\circ}$ values with $\mathrm{Li}^{+}$.

With protons as cycling ions, the interaction term was further reduced to 0.01. Again, the reduced interaction between successive charges could be accounted for by the charge accommodation at the cycling ion site. For the first reduction, the proton accommodated $67 \%$ of the injected charge, and the second proton accommodated $69 \%$ of the injected charge during the second reduction, thus significantly reducing the Coulombic interaction between successive charges. The benzene ring and the two oxygen atoms only accommodated, on average, 25 and $4 \%$, respectively. A somewhat surprising result from the charge distribution analysis was that, in the radical state, with proton cycling, the oxygen atom without a coordinating proton accommodated more charge (12\%) than the hydroxide oxygen (1\%). This is in contrast to the case with $\mathrm{Li}^{+}$where the $\mathrm{Li}$ coordinating oxygen became more electron-rich than the noncoordinating oxygen. We propose that the uncompensated oxygen charge in the radical state contributes to instability of the intermediate redox state, resulting in disproportionation of the semiquinone, in accord with the observed one-step $2 \mathrm{e} / 2 \mathrm{H}^{+}$ process.

When examining the substituted quinones, we found that electron-withdrawing substituents tended to increase the interaction term while electron-donating substituents decreased the interaction term, irrespective of the cycling ions (Figure 3). (Note that all atoms, including the substituents,

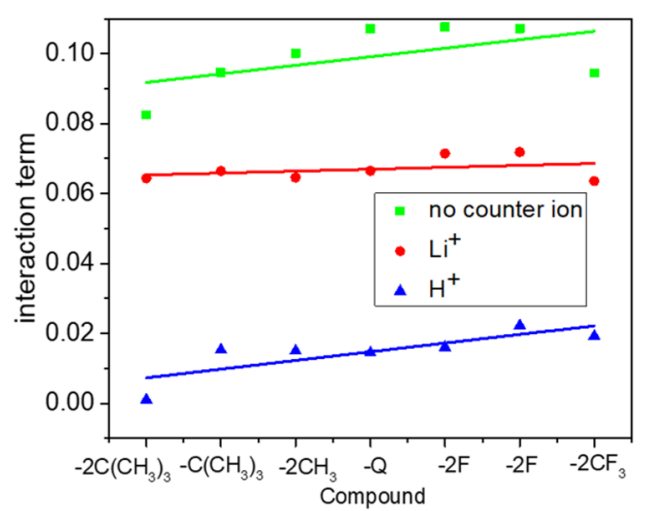

Figure 3. Interaction terms for substituted quinones with $\mathrm{TBA}^{+}$ (green), $\mathrm{Li}^{+}$(red), and $\mathrm{H}^{+}$cycling (blue). The substituents are arranged according to their electron-withdrawing power. Solid lines are guides for the eye.

were included in the interaction term.) This trend is in accordance with the observation that the separation between the first and second reduction redox peaks increased with the substituent's electron-withdrawing power. In the case of lithium ion cycling, the effect of this general trend was that the overall reaction changed from a simultaneous $2 \mathrm{e} / 2 \mathrm{Li}^{+}$ reduction, with electron-donating substituents, to two sequential $1 \mathrm{e} / 1 \mathrm{Li}^{+}$reductions, with electron-withdrawing substituents (Figure 2).

3.3.2. Quinone-Solvent Interaction. From the above discussion, it is clear that the cycling ion has a profound effect on quinone electrochemistry. However, the difference in behavior between the $\mathrm{H}_{2} \mathrm{SO}_{4} / \mathrm{H}_{2} \mathrm{O}$ electrolyte and the protonic pyridium triflate/pyridine/ $\mathrm{MeCN}$ electrolyte suggests that the solvent also affects quinone electrochemistry. In particular, we found the invariance of $E^{\circ \prime}$ with substitution as observed in water to be of particular interest as it affects the way we think about potential tuning in general. From an aprotic organic electrolyte to an aqueous electrolyte, the situation becomes complex due to the strong polarity of the $\mathrm{H}_{2} \mathrm{O}$ solvent. ${ }^{32}$ Smith's group found that the $E^{\circ \prime}$ of the $\mathrm{Q}^{\bullet-} /$ $\mathrm{Q}^{2-}$ redox couple in a $\mathrm{TBAPF}_{6} / \mathrm{DMF}$ electrolyte shifted positively to a large extent with the addition of water, while the $E^{\circ \prime}$ of the $\mathrm{Q} / \mathrm{Q}^{\bullet-}$ redox couple moved positively only slightly, and they concluded that solvent water hydrogen bonding had a greater effect on the $E^{\circ \prime}$ of the redox reaction of $\mathrm{Q}^{\bullet-} / \mathrm{Q}^{2-}$ than on that of $\mathrm{Q} / \mathrm{Q}^{\bullet-}{ }^{13}$ To investigate the specific solventquinone interactions, we conducted explicit solvent model calculations by explicitly including four $\mathrm{H}_{2} \mathrm{O}$ molecules in the solvent cage in the PCM (Scheme 2). Comparing the lowest unoccupied molecular orbitals (LUMOs) of the oxidized quinone and semiquinone, which are considered to be related to the first and second reduction potentials, ${ }^{33}$ respectively, we noted that the LUMO energies were less dependent on substitution with explicit water molecules included (Figure 4a), indicating that the quinone-solvent water interaction 
Scheme 2. Structure of Quinone in a Neutral State in an Explicit Implicit Solvent Model with Four Explicit Molecules Introduced ${ }^{a}$

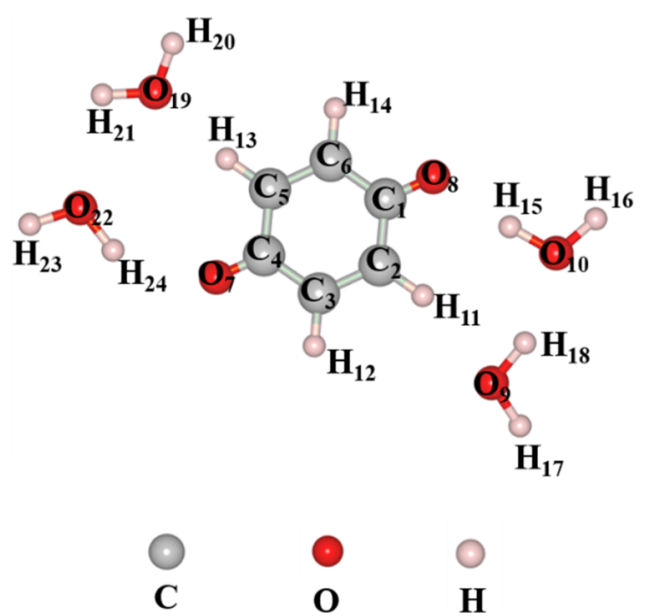

${ }^{a}$ For easy reading, the four water molecules around the carbonyl groups are marked $\mathrm{H}_{2} \mathrm{O}-9, \mathrm{H}_{2} \mathrm{O}-10, \mathrm{H}_{2} \mathrm{O}-19$, and $\mathrm{H}_{2} \mathrm{O}-22$, respectively.

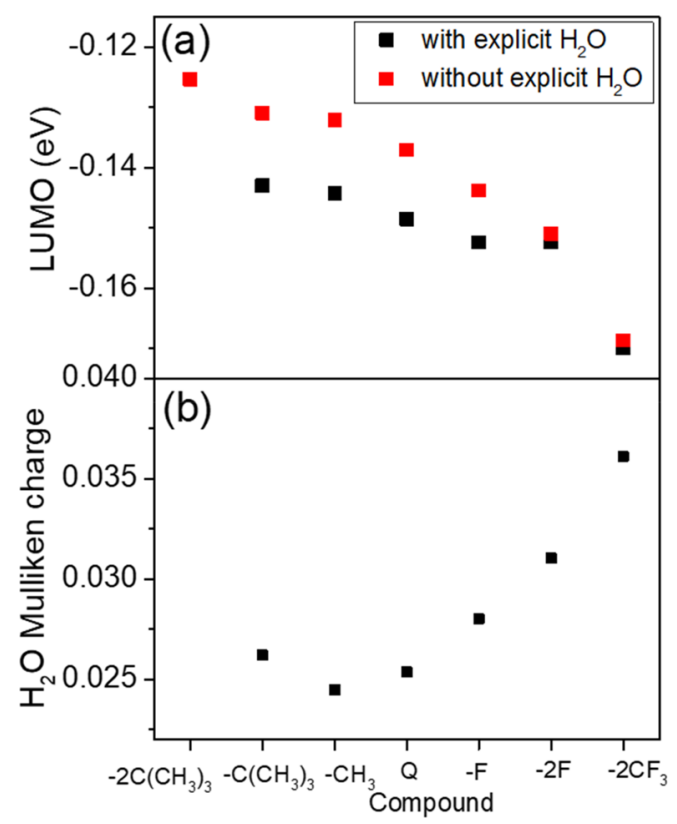

Figure 4. (a) Lowest unoccupied molecular orbital (LUMO) energy of quinone derivatives with and without explicit $\mathrm{H}_{2} \mathrm{O}$ molecules in the solvent cage. (b) Average Mulliken charge of $\mathrm{H}_{2} \mathrm{O}-10$ and $\mathrm{H}_{2} \mathrm{O}-22$ molecules at neutral state; $\mathrm{H}_{2} \mathrm{O}$ is named after the $\mathrm{O}$ number.

dampened the effect of substitution. In the quinone oxidized state, the water molecules located close to the carbonyl groups $\left(\mathrm{H}_{2} \mathrm{O}-10\right.$ and $\left.\mathrm{H}_{2} \mathrm{O}-22\right)$ donated electron density to the quinone molecule, as was evidenced by the positive net charge of these water molecules (Figure $4 \mathrm{~b}$ ), while the other two water molecules $\left(\mathrm{H}_{2} \mathrm{O}-9\right.$ and $\left.\mathrm{H}_{2} \mathrm{O}-19\right)$ did not. We averaged the net Mulliken charge of $\mathrm{H}_{2} \mathrm{O}-10$ and $\mathrm{H}_{2} \mathrm{O}-22$ and found that the average value increased with electron-withdrawing substitution, suggesting that the solvent electron-donating effect would increase with electron-withdrawing substitution. This effect would compensate for the electron-withdrawing effect of the substitutions and make $E^{\circ \prime}$ less sensitive to substitutions and could thus explain the breakdown of $E^{\circ \prime}$ dependence on electron-withdrawing substitution.

\section{CONCLUSION}

In this work, a series of quinone derivatives, substituted with electron-withdrawing and electron-donating substituents, were synthesized and characterized electrochemically (in $\mathrm{TBAPF}_{6} /$ $\mathrm{MeCN}, \mathrm{LiClO}_{4} / \mathrm{MeCN}$, pyridium triflate/pyridine/MeCN, and $\mathrm{H}_{2} \mathrm{SO}_{4} / \mathrm{H}_{2} \mathrm{O}$ ) and computationally (using DFT calculations). We have shown that quinone electrochemistry is heavily dependent on the charge-balancing ions. In $\mathrm{TBAPF}_{6} /$ $\mathrm{MeCN}$, all quinone derivatives showed two well-separated oneelectron reductions. $\mathrm{Li}^{+}$cycling positively shifted the $E^{\mathrm{O} \prime}$ value compared to the corresponding value observed in $\mathrm{TBAPF}_{6} /$ $\mathrm{MeCN}$. The separation between the first and second reductions was also significantly reduced in the $\mathrm{Li}^{+}$-based electrolyte, and for quinones with electron-donating substituents, a potential inversion between the first and second reductions was observed. $\mathrm{H}^{+}$cycling positively shifted the $E^{\circ}$ even further, and in all cases, the semiquinone intermediate state was unstable with respect to disproportionation. In addition, we have shown that the sensitivity to $E^{\circ \prime}$ tuning by substituting the quinone ring with electron-withdrawing/donating substituents was heavily dependent on the nature of the cycling ion as well as on the solvent. In particular, while there was a clear and direct correlation between $E^{\circ \prime}$ and the electron-withdrawing power of the substituent in an $\mathrm{MeCN}$ solution, the correlation was completely lost in aqueous solution. The indifference to substitution, which severely restricts the possibility of tuning the $E^{\circ \prime}$ of quinone in aqueous electrolytes, was traced to a counterbalancing electron donation from surrounding water molecules, effectively canceling out any electron-donating/-withdrawing effects of the substituents.

\section{ASSOCIATED CONTENT}

Supporting Information

The Supporting Information is available free of charge at https://pubs.acs.org/doi/10.1021/acs.jpcc.0c03632.

$\mathrm{CV}$ and SWV data, quinone formal potentials, and Mulliken charges (PDF)

\section{AUTHOR INFORMATION}

\section{Corresponding Author}

Martin Sjödin - Nanotechnology and Functional Materials, Department of Engineering Sciences, The Angström Laboratory, Uppsala University, SE-751 21 Uppsala, Sweden; 이이.org/ 0000-0003-4126-4347; Email: martin.sjodin@ angstrom.uu.se

\section{Authors}

Huan Wang - Nanotechnology and Functional Materials, Department of Engineering Sciences, The Ångström Laboratory, Uppsala University, SE-751 21 Uppsala, Sweden; 이이.org/ 0000-0001-8819-9453

Rikard Emanuelsson - Nanotechnology and Functional Materials, Department of Engineering Sciences, The Ångström Laboratory, Uppsala University, SE-751 21 Uppsala, Sweden; (1) orcid.org/0000-0002-4726-4121

Amitava Banerjee - Materials Theory Division, Department of Physics and Astronomy, Uppsala University, SE-751 21 Uppsala, Sweden; 이이.org/0000-0002-3548-133X 
Rajeev Ahuja - Materials Theory Division, Department of Physics and Astronomy, Uppsala University, SE-751 21

Uppsala, Sweden; (1) orcid.org/0000-0003-1231-9994

Maria Strømme - Nanotechnology and Functional Materials, Department of Engineering Sciences, The Angström Laboratory, Uppsala University, SE-751 21 Uppsala, Sweden; ㅈorcid.org/ 0000-0002-5496-9664

Complete contact information is available at:

https://pubs.acs.org/10.1021/acs.jpcc.0c03632

\section{Notes}

The authors declare no competing financial interest.

\section{ACKNOWLEDGMENTS}

This work was funded by the Swedish Energy Agency, the Carl Trygger Foundation, and the Research Council Formas. R.A. thanks the Swedish Research Council (VR); H.W. and A.B. especially thank the China Scholarship Council (CSC) for a Ph.D. study fellowship and the Carl Tryggers Stiftelse for Vetenskaplig Forskning (CTS), respectively. SNIC and HPC2N are also acknowledged for providing computing time.

\section{REFERENCES}

(1) Armand, M.; Tarascon, J.-M. Building Better Batteries. Nature 2008, 451, 652-657.

(2) Larcher, D.; Tarascon, J.-M. Towards Greener and More Sustainable Batteries for Electrical Energy Storage. Nat. Chem. 2015, 7, 19-29.

(3) Poizot, P.; Dolhem, F. Clean Energy New Deal for a Sustainable World: From Non-CO2 Generating Energy Sources to Greener Electrochemical Storage Devices. Energy Environ. Sci. 2011, 4, 20032019.

(4) Gao, X.-P.; Yang, H.-X. Multi-Electron Reaction Materials for High Energy Density Batteries. Energy Environ. Sci. 2010, 3, 174-189. (5) Ji, X.; Banks, C. E.; Silvester, D. S.; Wain, A. J.; Compton, R. G. Electrode Kinetic Studies of the Hydroquinone-Benzoquinone System and the Reaction between Hydroquinone and Ammonia in Propylene Carbonate: Application to the Indirect Electroanalytical Sensing of Ammonia. J. Phys. Chem. C 2007, 111, 1496-1504.

(6) Sterby, M.; Emanuelsson, R.; Mamedov, F.; Strømme, M.; Sjödin, M. Investigating Electron Transport in a PEDOT/Quinone Conducting Redox Polymer with in Situ Methods. Electrochim. Acta 2019, 308, 277-284.

(7) Åkerlund, L.; Emanuelsson, R.; Renault, S.; Huang, H.; Brandell, D.; Strømme, M.; Sjödin, M. The Proton Trap Technology-Toward High Potential Quinone-Based Organic Energy Storage. Adv. Energy Mater. 2017, 7, 1700259.

(8) Gamboa-Valero, N.; Astudillo, P. D.; González-Fuentes, M. A.; Leyva, M. A.; Rosales-Hoz, M. de J.; González, F. J. Hydrogen Bonding Complexes in the Quinone-Hydroquinone System and the Transition to a Reversible Two-Electron Transfer Mechanism. Electrochim. Acta 2016, 188, 602-610.

(9) Sereda, G.; Van Heukelom, J.; Koppang, M.; Ramreddy, S.; Collins, N. Effect of Transannular Interaction on the Redox-Potentials in a Series of Bicyclic Quinones. Beilstein J. Org. Chem. 2006, 2, 26.

(10) Tessensohn, M. E.; Hirao, H.; Webster, R. D. Electrochemical Properties of Phenols and Quinones in Organic Solvents Are Strongly Influenced by Hydrogen-Bonding with Water. J. Phys. Chem. C 2013, 117, 1081-1090.

(11) Emanuelsson, R.; Huang, H.; Gogoll, A.; Strømme, M.; Sjödin, M. Enthalpic versus Entropic Contribution to the Quinone Formal Potential in a Polypyrrole-Based Conducting Redox Polymer. J. Phys. Chem. C 2016, 120, 21178-21183.

(12) Emanuelsson, R.; Sterby, M.; Strømme, M.; Sjödin, M. An AllOrganic Proton Battery. J. Am. Chem. Soc. 2017, 139, 4828-4834.
(13) Quan, M.; Sanchez, D.; Wasylkiw, M. F.; Smith, D. K. Voltammetry of Quinones in Unbuffered Aqueous Solution: Reassessing the Roles of Proton Transfer and Hydrogen Bonding in the Aqueous Electrochemistry of Quinones. J. Am. Chem. Soc. 2007, $129,12847-12856$.

(14) Hui, Y.; Chng, E. L. K.; Chng, C. Y. L.; Poh, H. L.; Webster, R. D. Hydrogen-Bonding Interactions between Water and the One- and Two-Electron-Reduced Forms of Vitamin $\mathrm{K}_{1}$ : Applying Quinone Electrochemistry To Determine the Moisture Content of NonAqueous Solvents. J. Am. Chem. Soc. 2009, 131, 1523-1534.

(15) Walczak, M. M.; Dryer, D. A.; Jacobson, D. D.; Foss, M. G.; Flynn, N. T. PH-Dependent Redox Couple: Illustrating the Nernst Equation Using Cyclic Voltammetry. J. Chem. Educ. 1997, 74, 11951197.

(16) Strietzel, C.; Sterby, M.; Huang, H.; Strømme, M.; Emanuelsson, R.; Sjödin, M. An Aqueous Conducting Redox Polymer Based Proton Battery That Can Withstand Rapid Constant-voltage Charging and Sub-zero Temperatures. Angew. Chem., Int. Ed. 2020, 59, 9631-9638.

(17) Åkerlund, L.; Emanuelsson, R.; Hernández, G.; Ruipérez, F.; Casado, N.; Brandell, D.; Strømme, M.; Mecerreyes, D.; Sjödin, M. In Situ Investigations of a Proton Trap Material: A PEDOT-Based Copolymer with Hydroquinone and Pyridine Side Groups Having Robust Cyclability in Organic Electrolytes and Ionic Liquids. ACS Appl. Energy Mater. 2019, 2, 4486-4495.

(18) Frontana, C.; Vázquez-Mayagoitia, Á.; Garza, J.; Vargas, R.; González, I. Substituent Effect on a Family of Quinones in Aprotic Solvents: An Experimental and Theoretical Approach. J. Phys. Chem. A 2006, 110, 9411-9419.

(19) Wang, H.; Emanuelsson, R.; Liu, H.; Edström, K.; Mamedov, F.; Strømme, M.; Sjödin, M. Redox-State-Dependent Interplay between Pendant Group and Conducting Polymer Backbone in Quinone-Based Conducting Redox Polymers for Lithium Ion Batteries. ACS Appl. Energy Mater. 2019, 2, 7162-7170.

(20) Carney, T. J.; Collins, S. J.; Moore, J. S.; Brushett, F. R. Concentration-Dependent Dimerization of Anthraquinone Disulfonic Acid and Its Impact on Charge Storage. Chem. Mater. 2017, 29, 4801-4810.

(21) Guin, P. S.; Das, S.; Mandal, P. C. Electrochemical Reduction of Quinones in Different Media: A Review. Int. J. Electrochem. 2011, $2011,1-22$.

(22) Tong, L.; Chen, Q.; Wong, A. A.; Gómez-Bombarelli, R.; Aspuru-Guzik, A.; Gordon, R. G.; Aziz, M. J. UV-Vis Spectrophotometry of Quinone Flow Battery Electrolyte for in Situ Monitoring and Improved Electrochemical Modeling of Potential and Quinhydrone Formation. Phys. Chem. Chem. Phys. 2017, 19, 31684-31691.

(23) Becke, A. D. Density-functional Thermochemistry. III. The Role of Exact Exchange. J. Chem. Phys. 1993, 98, 5648-5652.

(24) Becke, A. D. Density-Functional Exchange-Energy Approximation with Correct Asymptotic Behavior. Phys. Rev. A: At., Mol., Opt. Phys. 1988, 38, 3098-3100.

(25) Lee, C.; Yang, W.; Parr, R. G. Development of the ColleSalvetti Correlation-Energy Formula into a Functional of the Electron Density. Phys. Rev. B: Condens. Matter Mater. Phys. 1988, 37, 785789.

(26) Hehre, W. J.; Ditchfield, R.; Pople, J. A. Self-Consistent Molecular Orbital Methods. XII. Further Extensions of GaussianType Basis Sets for Use in Molecular Orbital Studies of Organic Molecules. J. Chem. Phys. 1972, 56, 2257-2261.

(27) Francl, M. M.; Pietro, W. J.; Hehre, W. J.; Binkley, J. S.; Gordon, M. S.; DeFrees, D. J.; Pople, J. A. Self-consistent Molecular Orbital Methods. XXIII. A Polarization-type Basis Set for Second-row Elements. J. Chem. Phys. 1982, 77, 3654-3665.

(28) Karlsson, C.; Jämstorp, E.; Strømme, M.; Sjödin, M. Computational Electrochemistry Study of 16 Isoindole-4,7-Diones as Candidates for Organic Cathode Materials. J. Phys. Chem. C 2012, 116, 3793-3801.

(29) Sterby, M.; Emanuelsson, R.; Huang, X.; Gogoll, A.; Strømme, M.; Sjödin, M. Characterization of PEDOT-Quinone Conducting 
Redox Polymers for Water Based Secondary Batteries. Electrochim. Acta 2017, 235, 356-364.

(30) Hansch, C.; Leo, A.; Taft, R. W. A Survey of Hammett Substituent Constants and Resonance and Field Parameters. Chem. Rev. 1991, 91, 165-195.

(31) Lin, C.; Protasiewicz, J. D.; Smith, E. T.; Ren, T. Linear Free Energy Relationships in Dinuclear Compounds. 2. Inductive Redox Tuning via Remote Substituents in Quadruply Bonded Dimolybdenum Compounds. Inorg. Chem. 1996, 35, 6422-6428.

(32) Mensa-Bonsu, G.; Lietard, A.; Verlet, J. R. R. Enhancement of Electron Accepting Ability of Para -Benzoquinone by a Single Water Molecule. Phys. Chem. Chem. Phys. 2019, 21, 21689-21692.

(33) Cheng, L.; Assary, R. S.; Qu, X.; Jain, A.; Ong, S. P.; Rajput, N. N.; Persson, K.; Curtiss, L. A. Accelerating Electrolyte Discovery for Energy Storage with High-Throughput Screening. J. Phys. Chem. Lett. 2015, 6, 283-291. 